\title{
Pentingnya Penanaman Nilai-Nilai Budaya Lokal dalam Keluarga di Era Global
}

\author{
Sri Sudarsih \\ Fakultas Ilmu Budaya, Universitas Diponegoro \\ Jalan Prof Soedharto, SH. Tembalang Semarang 50275 \\ E-mail: srisudarsih012005@yahoo.com
}

\begin{abstract}
A global era whose existence cannot be denied brings logical consequences on every line of human life. Therefore, Javanese culture which has fundamental values is very relevant to study its relation to this global era. This research is a study in the field of philosophy related to Javanese cultural values. The method used by researchers is description and interpretation. One of the Javanese culture is the attitude of the Javanese people, namely the attitude of rila (sincere), temen (keep promises), watak (patience), and budi luhur (noble virtue) has a fundamental value meaning. These values becomes a parameter of one's quality. The quality of one's goodness can be measured by his practice of these values. These fundamental values are important to be realized in family life in this global era.
\end{abstract}

Keywords: Value, Javanese culture, family

\section{Pendahuluan}

Sejarah telah membuktikan bahwa budaya Jawa mempunyai daya lentur yang tinggi menghadapi hadirnya budaya asing yang masuk ke Indonesia khususnya Jawa. Ketika budaya Hindu masuk ke Jawa diterima sedemikian rupa sehingga terjadi kristalisasi nilai-nilai yang menjadi adat dan budaya Hindu diamalkan dalam kehidupan sehari-hari. Demikian juga ketika Budha masuk ke Indonesia juga diterima dengan baik sehingga terjadi akulturasi budaya yang selaras dengan kehidupan di masyarakat. Budaya ini merupakan kritalisasi nilai dari filsafat hidup nenek moyang berupa Candi Budha yaitu Candi Borobudur dan Candi Hindu yaitu Candi Prambanan. Candi Borobudur oleh UNESCO ditetapkan menjadi salah satu keajaiban dari tujuh keajaiban dunia. Hal ini membuktikan bahwa peninggalan nenek moyang memiliki nilai yang tinggi. Demikian juga kedatangan bangsa Eropa yang awalnya ingin berdagang, kemudian menjajah bangsa Indonesia membawa budaya baru. Kedatangan mereka juga mewarnai budaya Jawa.

Pada era globalisasi, perkembangan telekomunikasi dan informasi semakin pesat membawa dampak yang signifikan pada seluruh lini kehidupan masyarakat Indonesia. Globlisasi secara langsung maupun tidak langsung dapat memengaruhi bangsa Indonesia pada umumnya dan orang Jawa pada khususnya. Pengaruh terhadap perilaku, sikap hidup, dan maupun pandangan hidupnya. Penelitian ini dibatasi pada budaya lokal yaitu budaya Jawa. Persoalannya adalah apa pentingnya penanaman nilai-nilai budaya Jawa dalam keluarga di era global? 


\section{Pembahasan}

\subsection{Nilai-Nilai Budaya Jawa}

Istilah nilai berasal dari bahasa Inggris value. Dalam bidang filsafat nilai mengacu pada kata benda abstrak yang dimaknai 'keberhargaan' atau 'kebaikan', sedangkan nilai sebagai kata kerja diartikan suatu tindakan kejiwaan tertentu dalam menilai dan melakukan penilaian (Kaelan, 2001: 174). Hakikat nilai adalah kualitas yang melekat pada suatu objek.

Nilai menurut Driyarkara ada lima : nilai vital, nilai keindahan, nilai kebenaran, nilai moral, dan keagamaan (Driyarkara, 1980: 120). Nilai masih perlu diaktifkan dalam kehidupan nyata. Sedangkan kebudayaan menurut Ki Hadjar Dewantara adalah segala sesuatu yang berhubungan dengan budaya. Budaya berasal dari kata budi sebagai jiwa yang telah matang. Budaya atau kebudayaan merupakan buah budi manusia (Ki Hadjar Dewantara, 1967: 85).

Berdasarkan pada pemahaman nilai dan budaya maka nilai-nilai budaya Jawa adalah kualitas dari hasil budi manusia yang berkembang pada masyarakat Jawa. Banyak ahli yang merumuskan tentang konsep budaya, ciri-ciri, dan hakikatnya tetapi dalam penelitian ini dibatasi pada salah satu sifat dari hakikat budaya Jawa khususnya yang berkaitan dengan sikap etis orang Jawa. Sikap etis itu dirumuskan oleh R. Soenarto seperti yang dikutip Budiono Heru Satoto (1984:79-81) sebagai berikut :

a. Rila atau rela. Rila memiliki makna keikhlasan menyerahkan semua milik, kekuasaan, dan hasil karyanya pada Tuhan.

b. Temen memiliki arti menepati janji atau ucapannya sendiri.

c. Watak sabar atau sifat sabar memiliki arti tingkah laku yang baik.

d. Budi luhur memiliki arti berupaya menjalankan hidup dengan tabiat, watak, dan sifatsifat yang dimiliki Tuhan.

Sikap etis seperti rila, temen, watak sabar, dan budi luhur merupakan nilai moral yang harus dimiliki setiap orang. Nilai-nilai tersebut memiliki makna mendalam yang telah hidup dan berkembang dalam kehidupan masyarakat Jawa. Empat sikap tersebut menjadi parameter kualitas pribadi seseorang apakah seseorang sudah menjalankan kehidupan secara baik dan benar.

\subsection{Pengertian Keluarga}

Keluarga terbentuk melalui ikatan perkawinan. Undang-undang no. 1 tahun 1974 pada bab I pasal 1 dan penjelasannya menyebutkan:

Perkawinan adalah ikatan lahir batin antara seorang pria dengan seorang wanita sebagai suami istri dengan tujuan membentuk keluarga (rumah tangga) yang bahagia dan kekal berdasarkan Ketuhanan Yang Maha Esa. Tujuan perkawinan adalah membentuk keluarga yang bahagia dan kekal. Untuk itu suami isteri perlu saling membantu dan melengkapi, agar masing-masing dapat mengembangkan kepribadiannya membantu dan mencapai kesejahteraan spiritual dan material (Departemen Hukum dan Hak Asasi Manusia, 2016: 2, 24).

Keluarga merupakan kelompok terkecil dalam masyarakat. Kondisi suatu keluarga berpengaruh luas kepada lingkungan sosialnya. Keluarga yang harmonis dapat memengaruhi juga kerharmonisan dalam lingkungan sosialnya. Khairudin menjelaskan bahwa keluarga memiliki interrelasi dengan masyarakat di luarnya (Khairuddin, 2008: 25). 


\subsection{Era Global}

Martin Albrow, seperti yang dikutip M. Sastrapratedja, mengemukakan ada empat aspek globalisasi : (a) Nilai yang memengaruhi perilaku anggota masyarakat dewasa ini berkaitan dengan nilai-nilai yang menyebar di seluruh dunia (globalism; (b) Pencitraan, informasi, dan komoditi dari berbagai wilayah dunia tersedia. Berbagai kekuatan dunia dan peristiwa dunia dapat memengaruhi kehidupan lokal; (c) Informasi dan teknologi komunikasi mengatasi jarak dan waktu; (d) Pengaturan secara global memungkinkan orang berinteraksi tanpa sekat negara. Sementara aktivitas dan rutinitas tetap berjalan seperti biasa. Intinya globalisasi telah membawa perubahan kepada proses pembentukan masyarakat baru, dengan sistem yang baru pula.

\subsection{Realisasi Penanaman Nilai-Nilai Budaya Lokal Dalam Keluarga}

Realisasi terhadap nilai keikhlasan atau rila bersifat spiritual memiliki makna berserah diri kepada Tuhan. Keikhlasan mengiringi sikap narima yang dilandasi sikap kerja keras secara optimal yang kemudian menerima hasilnya dengan rasa bangga.

Rila ini dimasyarakat selalu dikaitkan dengan tindakan mupus yang juga berarti berserah diri kepada Tuhan, tapi bukan berarti sikap fatalistik. Karena sikap fatalistik lebih cenderung berserah diri tanpa dilandasi usaha sekuat tenaga. Mupus sendiri artinya adalah sikap yang berkesuaian dengan pupus. Padahal pupus secara harafiah adalah daun muda yang masih kuncup yang ingin berkembang yang selalu mencari arah "Cahaya,". Sikap mupus pun artinya juga berserah diri yang disandarkan kepada "Cahaya" tadi. Cahaya disini yang dimaksudkan adalah cahaya Ilahi.

Nilai keikhlasan ini menjadi landasan bersikap dan bertingkah laku setiap individu menghadapi berbagai terpaan arus globalisasi. Jika nilai-nilai global dapat meningkatkan harkat dan martabat kemanusiaan maka harus diraih.

Sikap temen berarti menepati janji pada diri sendiri, sesama maupun Tuhan. Sikap temen oleh orang Jawa dirumuskan dalam pepatah Sapa sing temen ing kana bakal tinemu artinya orang yang menepati janji maka akan mendapatkan melebihi dari yang diharapkan. Pertanggung jawaban sikap temen ini bukan saja terhadap diri sendiri tetapi secara sosial dan spiritual juga. Oleh karena itu penerapan teknolgi informasi yang berkembang secara cepat harus dipertanggung jawabkan juga terhadap tiga hal tadi.

Secara sederhana dapat dirumuskan temen adalah kesesuaian antara apa yang dipikirkan atau dikehendaki dengan apa yang diucapkan maupun dengan yang dilakukan sama maksud dan tujuannya, tidak ada maksud tersembunyi dibalik apa yang dilakukan. Sehingga orang lain bisa mempercayai sepenuhnya dengan apa yang dilakukannya.

Watak atau sikap sabar harus dimiliki oleh setiap individu. Sabar dalam pengertian hati-hati, optimis, dan kuat terhadap tantangan baru. Globalisasi yang tidak semuanya bisa diterima dengan kondisi Indonesia harus dihadapi dengan dengan kesabaran yang tinggi. Berbagai paham yang bertentangan dengan nilai-nilai yang sudah mapan harus dieliminasi dengan sikap yang sabar.

Sikap budi luhur merupakan sikap mental yang menginginkan keseluruhan nilai harus dikembalikan dengan nilai-nilai spiritual. Hal ini didasarkan pada alasan bahwa sikap hidup yang paling mendasar bagi orang Jawa adalah selalu berpegang pada nilai spiritual.

Keseluruhan nilai tersebut harus ditanamkan dilingkungan keluarga sebagai sistem nilai dalam membentuk karakter setiap anggota keluarga. Nilai-nilai yang membentuk karakter tersebut pada gilirannya akan mewarnai dan mendasari terbentuknya masyarakat baru tadi. 


\section{Simpulan}

Budaya lokal yang merupakan sintesa dari perkembangan nilai-nilai budaya tradisional mampu menjadi benteng dari pengaruh residu budaya global. Budaya Jawa yang bersifat spiritualis merupakan antitesa dari budaya global yang lebih cenderung liberal dan materialis.

Untuk itulah budaya Jawa tetap harus mengawal perkembangan dan pengaruh budaya global agar tidak kehilangan arah perkembangan budaya yang tetap mempunyai nilai yang menjunjung harkat dan martabat manusia seutuhnya.

\section{Daftar Pustaka}

Budiono Heru Satoto, 1984, Simbolisme dalam Budaya Jawa, Hanindita, Yogyakarta.

Driyarkara, 1980, Driyarkara Tentang Pendidikan, Kanisius, Yogyakarta.

Kaelan, 2001, Pendidikan Pancasila, Paradigma, Yogyakarta.

Khairuddin, 2008, Sosiologi Keluarga, Liberty, Yogyakarta.

Ki Hadjar Dewantara, 1967, Ki Hadjar Dewantara Tentang Pendidikan, Taman Siswa, Yogyakarta.

Koentjaraningrat, 1986, Kebudayaan Mentalitet Dan pembangunan, Gramedia, Jakarta.

Sastrapratedja, 1993, "Pendidikan Nilai" dalam Pendidikan Nilai Memasuki Tahun 2000, Gramedia, Jakarta.

\section{Peraturan Peundangan}

Departemen Hukum dan Hak Asasi Manusia, 2016, Undang-Undang R.I. Nomor 1 Tahun 1974 tentang Perkawinan dan Kompilasi Hukum Islam, Citra Umbara, Bandung. 